\title{
Temporal variability of atmospheric turbidity and DNI attenuation in the sugarcane region, Botucatu/São Paulo/Brazil
}

\author{
Cícero Manoel dos Santos, João Francisco Escobedo*
}

Rural Engineering Department, FCA/UNESP, Botucatu, São Paulo, Brazil

\section{A R T I C L E I N F O}

\section{Article history:}

Received 9 February 2016

Received in revised form 2 July 2016

Accepted 8 July 2016

Available online 10 July 2016

\section{Keywords:}

Atmospheric transparency

Aerosols

Water vapor

Pollution

Direct Normal Irradiance

\begin{abstract}
A B S T R A C T
In this study, attenuation of direct normal solar irradiance (DNI) in Botucatu / São Paulo, an area under the influence of local and adjacent agricultural burning, is expressed using the Linke's turbidity factor (TL) in the period from 1996 to 2008. Two methodologies represented as $\mathrm{TL}_{\mathrm{Dj}}$ and $\mathrm{TL}_{\mathrm{Li}}$ were used. Temporal variability (hourly average for the season and monthly average) is presented. Turbidity was correlated with wind speed and air temperature. Frequency distribution and cumulative frequency are analyzed to determine turbidity predominance levels in the local atmosphere. Optical depth information of aerosols at $550 \mathrm{~nm}\left(\mathrm{AOD}_{550 \mathrm{~nm}}\right)$ and water vapor were obtained by the Terra satellite using the MODIS sensor. The highest degree of DNI transmission is observed in the morning. Close to solar noon, transmission is smaller (greatest TL value). Diurnal TL variability is more evident in the hot period than in the cold period. May and June were the months of lowest DNI attenuation (highest atmospheric transparency). The highest DNI attenuation occurs in spring ( $\mathrm{TL}_{\mathrm{Dj}}=4.22 \pm 0.05$ and $\left.\mathrm{TL}_{\mathrm{Li}}=4.65 \pm 0.06\right)$ and summer $\left(\mathrm{TL}_{\mathrm{Dj}}=4.27 \pm 0.14\right.$ and $\left.\mathrm{TL}_{\mathrm{Li}}=4.69 \pm 0.15\right)$. Wind speed and air temperature were positively correlated with TL. In $>28 \%$ of hours of clear sky, turbidity exceeded the value of 4.0. The region of Botucatu seems to be influenced by water vapor and aerosols from different origins. This study concludes that these factors significantly reduce DNI incidence on the surface, with higher atmospheric transparency in the cold period and lower atmospheric transparency in the warm period.
\end{abstract}

() 2016 Elsevier B.V. All rights reserved.

\section{Introduction}

Direct normal solar irradiance (DNI) has essential applications in solar concentration technology, such as climate forcing and controller of terrestrial biodiversity (Batlles et al., 2000). When crossing a cloudless atmosphere, DNI is attenuated by two main processes: scattering by aerosols and absorption by water vapor, especially at visible and infrared wavelengths. Aerosols are tiny solid or liquid particles suspended in the air that follow the movement of air masses and can have terrestrial origin (agricultural burning, industrial smoke, dust storms, volcanic eruptions) and marine origin such as sea spray (López and Batlles, 2004). In clear sky conditions, the concentration of aerosols and water vapor content in the atmosphere affects the magnitude and variability of DNI (Gueymard, 2012). Aerosols and water vapor affect the level of atmospheric transparency, and attenuation caused in DNI is called turbidity.

Determining atmospheric turbidity requires detailed DNI measures, both of broadband and spectral bands (Salazar, 2011; Ellouz et al., 2013). Acquisition and maintenance of these sensors are almost

\footnotetext{
* Corresponding author at: Faculdade de Ciências Agronômicas (FCA/UNESP), Laboratorio de Radiometria Solar, Departmento de Engenharia Rural, Fazenda Lageado, Rua José Barbosa de Barros, n 1780, Botucatu/SP 18.610-307, Brazil.

E-mail address: escobedo@fca.unesp.br (J.F. Escobedo).
}

unfeasible due to the high cost of importing and maintenance (Dos Santos et al., 2014; Souza et al., 2016). Therefore, atmospheric turbidity is usually estimated by parametric models.

Typically, atmospheric turbidity in clear sky conditions is represented by the Linke's turbidity factor (TL) or Ångström turbidity coefficient $(\beta)$. TL referes to the total spectrum and describes optical tickness in the atmosphere as a result of two distinct combinations, absorption by water vapor and scattering by particulate matter in a dry and clear atmosphere (Kasten, 1996; El-Metwally, 2013). Based on this fact, TL is adequate to characterize total attenuation by the atmosphere (Kasten, 1980). Because the turbidity coefficient $(\beta)$ refers to the number of aerosols in the atmosphere, it is accepted as a representative index of turbidity caused by aerosols and corresponds to the aerosol optical depth in $1 \mu \mathrm{m}$ (Masmoudi et al., 2002). For convenience of use and ability to represent optical thickness of a dry and clean atmosphere, TL is often used as the first option (Ellouz et al., 2013). Calculating turbidity is important in the modeling of local climate in climate studies, air pollution studies, indirect measure of DNI, indirect measure of the concentration of particulates suspended in the air, and water vapor that absorbs, reflects, or scatters solar radiation (López and Batlles, 2004; Trabelsi and Masmoudi, 2011).

TL has been reported for numerous places (Hussain et al., 2000; Formenti et al., 2002; Diabaté et al., 2003; Polo et al., 2009a; Eltbaakh 
et al., 2012; Bertin and Frangi, 2013; Inman et al., 2015; Khalil and Shaffie, 2016). Using hourly data from nine Spanish regions, Polo et al. (2009b) proposed and evaluated a methodology to estimate daily Linke's turbidity in clear sky conditions based on measures of global horizontal irradiance at noon. The authors reported relative root mean square deviation (rRMSE) from $12.0 \%$ to $30.9 \%$. In Greece, Rapti (2000) used data of global and diffuse solar radiation to analyze diurnal and seasonal variations of atmospheric turbidity using TL. Diurnal and seasonal fluctuations of atmospheric transparency had minimum values in summer afternoons, and maximum values in winter mornings. In Thailand, Chaiwiwatworakul and Chirarattananon (2004) determined and analyzed atmospheric turbidity based on TL and $\beta$ indices using two-and-a-half-year-long measures. Atmospheric turbidity was low and stable during the dry season and high in the rainy season (March to August). Turbidity increases in the morning at noon and decreases during the afternoon. Annual mean values for TL and $\beta$ were 3.306 and 0.098 , respectively. However, studies on the temporal variability of TL and atmospheric transparency in Brazil are few, particularly for the state of São Paulo. In studies on the atmosphere of Rio de Janeiro, Brazil, Flores et al. (2015) calculated the atmospheric turbidity based on the Ångström turbidity coefficient $(\beta)$ and showed a decrease in summer months. The authors highlighted the wide availability of water vapor resulting from maritime influences and the great plant area.

Responsible for emitting large amounts of aerosols and gases into the atmosphere, burning of native forests for agricultural production and use of agricultural practices are still common activities in Brazil (Oliveira et al., 2011). This paper aims at determining TL under clear sky conditions in the agro-industrial region of Botucatu, state of São Paulo, where the economy is based on industry, agricultural activities (production of sugar and alcohol) and trade. Two Linke's turbidity methodologies $\left(\mathrm{TL}_{\mathrm{Dj}}\right.$ and $\left.\mathrm{TL}_{\mathrm{Li}}\right)$ are used and compared in order to analyze their effect and influence on the turbidity level. Correlation between turbidity and wind speed and air temperature was shown. Analyses of turbidity, frequency of occurrence, and cumulative frequency seem to characterize the turbidity index with atmospheric conditions. This work evaluates the rising pollution levels in the atmosphere of Botucatu, highlighting the period of lower atmospheric transparency (higher turbidity), likely factors responsible for the DNI attenuation and likely places of origin. This study also shows the trend of turbidity variability.

\section{Materials and methods}

\subsection{Description of location and climate}

Data used in this study were obtained from the solar Radiometry Station at the College of Agricultural Sciences from Botucatu, FCA/ UNESP ( $22^{\circ} 53^{\prime} 09^{\prime \prime} \mathrm{S}, 48^{\circ} 26^{\prime} 42^{\prime \prime} \mathrm{W}$ and average altitude of $786 \mathrm{~m}$ ). Botucatu is a municipality located in the Midwestern region of São Paulo state (Fig. 1), with a total area of $1482.642 \mathrm{~km}^{2}$ and estimated population in 2015 of approximately 139,483 inhabitants (IBGE, 2015). The city has high altitude gradient between 400 and $500 \mathrm{~m}$ in the lowest region (peripheral depression) and between 700 and 900 in the mountain region (Western Highlands). This difference causes changes in air temperature and winds. Distant $221 \mathrm{~km}$ from the Atlantic Ocean and $235 \mathrm{~km}$ from the capital São Paulo, with Savanna and Atlantic forest biome, Botucatu features warm temperate climate (mesothermal), hot and humid summer with high precipitation, and dry winter (Escobedo et al., 2011). According to the Köppen's climatic classification, based on monthly pluviometric and thermometric data, the climate of the Botucatu region is Cwa, characterized by the tropical climate of altitude, with rain in the summer and drought in the winter and mean temperature of the hottest month higher than $22^{\circ} \mathrm{C}(\mathrm{CPA}, 2016)$. With the Cwa climate predominantly in all central region, São Paulo state has seven distinct climatic types, mostly humid climate.

From October to March, rainfall is of microclimatic nature, from the free convection process and macroclimatic events as a result of the convergence of humid air masses coming from the Amazon region and southern Atlantic Ocean, which leads to the formation of the South Atlantic Convergence Zone (SACZ) and Frontal Systems (Jones et al., 2004; Reboita et al., 2010; Teramoto and Escobedo, 2012). From June to September, the central region of Brazil is dominated by an area of high pressure, low rainfall, and light winds in the lower troposphere, with convection in the Amazon moved to the northwestern part of South America (Freitas et al., 2005; Satyamurty et al., 1998). In the months of dry season, especially in August and September, the burning practice of sugarcane in cities nearby Botucatu is observed, which is held to harvest stalks (Codato et al., 2008). Because of burning, there is a significant increase in particulate concentrations in the local atmosphere (Allen et al., 2004). There is an additional load of aerosols from

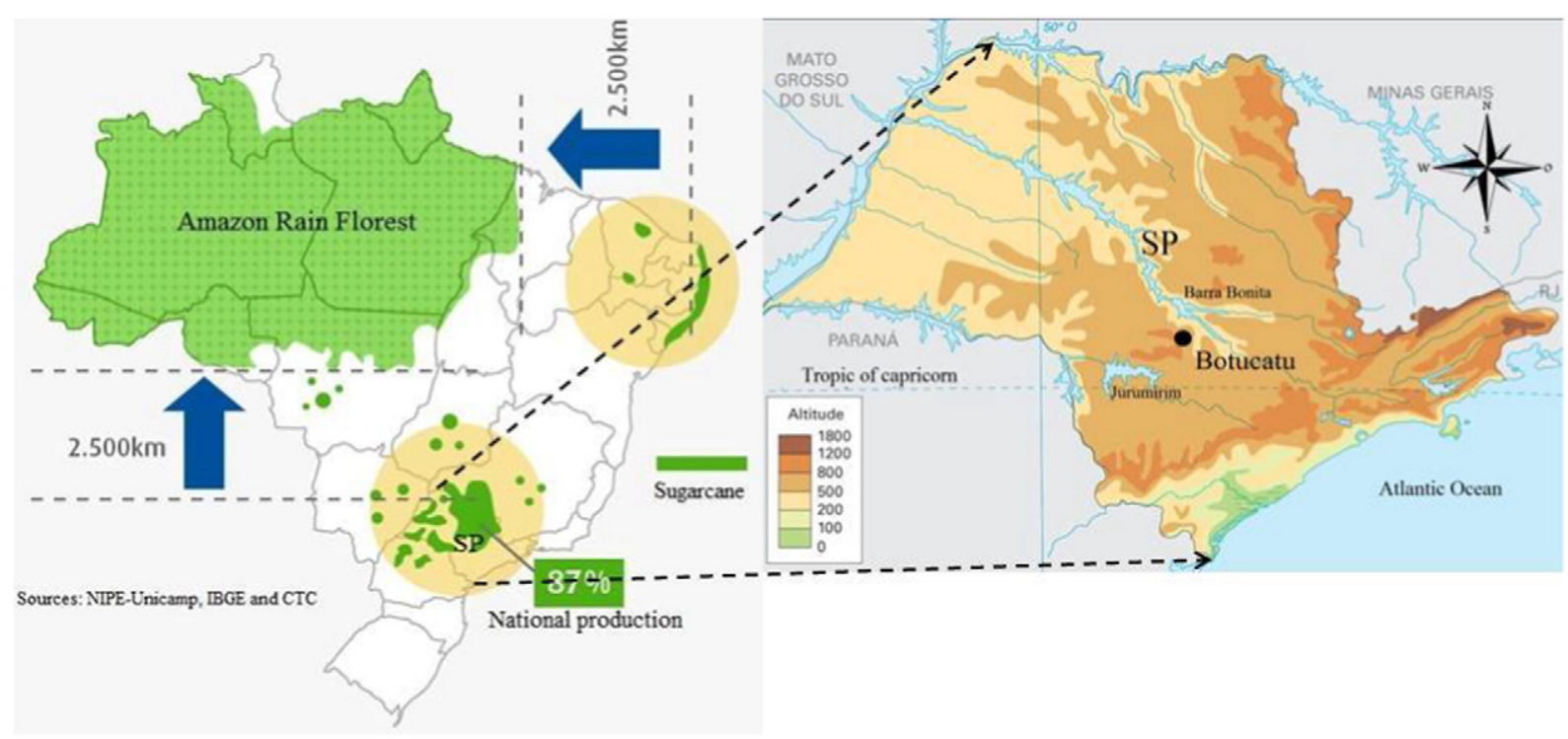

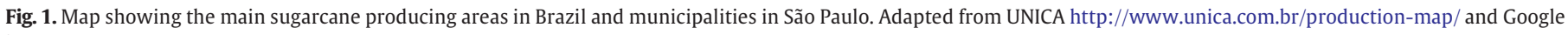
images. 
burning brought from the Amazon region of Bolivia, Paraguay, and Argentina to southern Brazil through atmospheric circulation (Videla et al., 2013; Portillo-Quintero et al., 2013). Almost all fires are caused by humans, whether on purpose or accidentally. Thus, the effect of aerosols can extrapolate from local scale and be decisive in the pattern of planetary redistribution of energy from the tropics to mid and high latitudes through convective transport processes (Freitas et al., 2005), resulting in changes in the hydrological cycle, due to changes in atmospheric temperature and cloud structure.

The presence of two hydroelectric dams, Jurumirim $\left(23.15^{\circ} \mathrm{S}\right.$; $\left.48.04^{\circ} \mathrm{W}\right)$ and Barra Bonita $\left(22.37^{\circ} \mathrm{S} ; 48.19^{\circ} \mathrm{W}\right)$ next to Botucatu, is worth mentioning. Jurumirim dam is $70 \mathrm{~km}$ away from Botucatu and has a reservoir of approximately $449 \mathrm{~km}^{2}$. The Barra Bonita dam, $30 \mathrm{~km}$ away from Botucatu, is $308 \mathrm{~km}^{2}$. Their structures represent changes in land cover and local microclimate. Changes of this magnitude cause significant interference in the turbulence of the atmosphere in micro- and mesoscale, modifying the radiation balance and microphysics of clouds (Rosenfeld, 1999).

\subsection{Database and model}

\subsubsection{Description of measures}

In the TL calculation, DNI measures were obtained from February 1996 to December 2008, through an Eppley NIP pyrheliometer coupled to an Eppley solar tracker ST3. Global solar irradiance $\left(\mathrm{R}_{\mathrm{G}}\right)$ was monitored by an Eppley pyranometer PSP and diffuse solar irradiance $\left(R_{D}\right)$ by an Eppley pyranometer PSP with a $40 \mathrm{~cm}$ radius and a $10 \mathrm{~cm}$ width ring (Dal Pai et al., 2014). All sensors were connected to a Campbell Datalogger CR1000 programmed to store averages every $5 \mathrm{~min}$. The sensors were annually calibrated by the comparative method (WMO, 2008). Hourly clear sky values were used for DNI. As atmospheric turbidity is an index for clear sky conditions, the criteria used in the selection of data to be applied in the models were based on Karayel et al. (1984). The criteria adopted for clear sky are as follows: DNI that exceeds $200 \mathrm{Wm}^{-2}$ and a ratio of diffuse irradiance to global irradiance of $<1 / 3$. It was considered that the atmospheric transmissivity $R_{G}$ (kt) could not be $<0.675$.

Optical depth values of aerosol at $550 \mathrm{~nm}\left(A_{0} D_{550 \mathrm{~nm}}\right)$ and water vapor were used in this study. AOD550 values were obtained by the Terra satellite using the MODIS sensor (Moderate Resolution Imaging Spectroradiometer), which makes measurements in the Botucatu region between 10:00 UTC and 11:00 UTC, and are regarded as daily values. The error expected for AOD550 provided by MODIS is: $\Delta\left(A_{0 D} D_{550}\right)=0.05 \pm 0.15\left(A_{0 D} D_{550}\right)$ (Remer et al., 2008). Water vapor data were obtained from the MODIS sensor aboard the Terra satellite. Water vapor value by MODIS has an error from 5\% to $10 \%$ (Gao and Kaufman, 2003). MODIS sensor data were downloaded from atmospheric products GIOVANNI (http://disc.sci.gsfc.nasa.gov/giovRNAi/overview/index.html) to an area of $0.2^{\circ}$ latitude $\times 0.2^{\circ}$ longitude around the measurement location. AOD550 and water vapor data were separated for clear sky conditions.

\subsubsection{Linke's turbidity (TL)}

Linke's turbidity (TL) (Linke, 1922) expresses the number of atmospheres (clean and dry) that produce, at the direct irradiance on top of the atmosphere, attenuation similar to an actual atmosphere (Pedrós et al., 1999; Hussain et al., 2000). Modifications and improvements have been suggested for TL (Kasten, 1996; Zakey et al., 2004; Mavromatakis and Franghiadakis, 2007). In this work, TL was calculated using methodologies (Djafer and Irbah, 2013) and (Li and Lam, 2002), represented as $\mathrm{TL}_{\mathrm{Dj}}$ and $\mathrm{TL}_{\mathrm{Li}}$, respectively.

\subsubsection{Methodology $\left(T L_{D j}\right)$}

Linke's turbidity (Djafer and Irbah, 2013) $\left(\mathrm{TL}_{\mathrm{Dj}}\right)$ is determined by the equation

$\mathrm{TL}_{\mathrm{Dj}}=T_{\mathrm{lk}} \times \frac{\frac{1}{\delta_{\mathrm{Ra}}\left(m_{\mathrm{a}}\right)}}{\frac{1}{\delta_{\mathrm{Rk}}\left(m_{\mathrm{a}}\right)}}$

where $T_{\mathrm{lk}}$ is a TL correction factor (Eq. (2)) and it is related to the direct solar irradiance (Trabelsi and Masmoudi, 2011; Kasten, 1980), $\delta_{\mathrm{Rk}}\left(m_{\mathrm{a}}\right)$ and $\delta_{\mathrm{Ra}}\left(m_{\mathrm{a}}\right)$ are both Rayleigh integral optical thickness. $\delta_{\mathrm{Rk}}\left(m_{\mathrm{a}}\right)$ is the Rayleigh integral optical thickness (dimensionless) (Eq. (3)) given by Kasten (1980), and $\delta_{\mathrm{Ra}}\left(m_{\mathrm{a}}\right)$ is the integral optical thickness (dimensionless) (Eq. (4)) given by Louche et al. (1986) and adjusted by Kasten (1996). The subscript $k$ represents the "Kasten" author, and the subscript $a$ represents the word "adjusted." The new adjustment was necessary because Kasten (1980), initially, had taken into cosideration only the molecular dispersion and ozone absorption. Absorption by the permanent atmospheric gases was not included into the calculations leading to smaller values of the integral optical thickness (Mavromatakis and Franghiadakis, 2007).

$T_{\mathrm{lk}}=[0.90+9.40 \times \sin (h)] \mathrm{x}\left\{2 \times\left[\ln \left(\mathrm{I}_{0}(h) \times\left(\frac{R_{0}}{R}\right)\right)\right]-\ln [\mathrm{DNI}(h)]\right\}$

where $h$ is the solar elevation angle (degrees), $I_{0}(h)$ is the solar constant $\left(1367 \mathrm{Wm}^{-2}\right)$, DNI $(h)$ is the direct solar irradiance in the measured incidence $\left(\mathrm{Wm}^{-2}\right)$, and $R_{0}$ and $R$ are the instant distance and the average distance between earth and sun, respectively. The $R_{0} / R$ ratio is called the eccentricity correction factor of the Earth's orbit $\left(E_{0}\right)$ (Iqbal, 1983).

$$
\begin{aligned}
\frac{1}{\delta_{\mathrm{Ra}}\left(m_{\mathrm{a}}\right)}= & 6.6296+1.7513 \times m_{\mathrm{a}}-0.1202 \times m_{\mathrm{a}}^{2}+0.0065 \\
& \times m_{\mathrm{a}}^{3}-0.00013 \times m_{a}^{4} \\
\frac{1}{\delta_{\mathrm{Rk}}\left(m_{\mathrm{a}}\right)}= & 9.40+0.90 \times m_{\mathrm{a}}
\end{aligned}
$$

$m_{\mathrm{a}}$ is the optical mass of the actual pressure given equation:

$m_{\mathrm{a}}=m_{\mathrm{r}} \times\left(\frac{p}{p_{0}}\right)$

$m_{\mathrm{r}}$ is the relative optical mass defined as a function of the solar elevation angle $(h)$ in degrees (Cañada et al., 1993):

$m_{r}=\left[\sin (h)+0.15 \times(3.885+h)^{-1.253}\right]^{-1}$

The $p / p_{0}$ ratio is the relationship between local pressure and standard pressure (at sea level) and was calculated as a function of the local altitude $(\mathrm{H})$ in meters (Iqbal, 1983) by the expression

$\frac{p}{p_{0}}=\exp (-0.0001184 \times H)$

\subsubsection{Methodology $\left(T L_{L i}\right)$}

The TL calculation using ( $\mathrm{Li}$ and Lam, 2002) $\left(\mathrm{TL}_{\mathrm{Li}}\right)$ arises from the definition that DNI for the entire solar spectrum and under clear sky condition can be calculated:

$\operatorname{DNI}(h)=I_{0}(h) \exp \left(-\mathrm{TL}_{\mathrm{Li}} \delta_{\mathrm{Rk}}\left(m_{\mathrm{a}}\right)\right)$

Reorganized Eq. (8) to $\mathrm{TL}_{\mathrm{Li}}$ :

$T L_{\mathrm{Li}}=\frac{\ln \left(\frac{I_{0}(h)}{\operatorname{DNI}(h)}\right)}{\left[\delta_{\mathrm{Rk}}\left(m_{\mathrm{a}}\right)\right]}$ 
Table 1

Types of atmosphere for different levels of atmospheric turbidity.

\begin{tabular}{lll}
\hline Types of atmosphere & TL & Visibility $(\mathrm{km})$ \\
\hline Rayleigh and pure atmosphere & 1 & 340 \\
Clear, warm air & 2 & 28 \\
Turbid, moist, warm air & 3 & 11 \\
Polluted atmosphere & $4-8$ & $<5$ \\
\hline
\end{tabular}

Parameters $\delta_{\mathrm{Rk}}\left(m_{\mathrm{a}}\right), I_{0}(\mathrm{~h})$, and $\mathrm{DNI}(\mathrm{h})$ have been previously defined. $\mathrm{TL}_{\mathrm{Li}}$ was used to calculate the optical mass and actual pressure $\left(m_{\mathrm{a}}\right)$ (Eq. (5)), and $m_{\mathrm{r}}$ is a function of the zenith angle $(Z)$ in degrees (Eq. (10)):

$m_{r}=\left[\cos Z+0.15 \times(93.885-Z)^{-1.253}\right]^{-1}$

Considering the TL equations above, $\mathrm{TL}_{\mathrm{Dj}}$ and $\mathrm{TL}_{\mathrm{Li}}$ values can be easily obtained directly from DNI measurements performed with the pyrheliometer installed in Botucatu.

Typical TL values usually range from 1 to 10 ; higher values mean that DNI is more attenuated and the atmosphere has high concentration of aerosol and high water vapor content (less transparent atmosphere). This study will consider the characterization of atmosphere types associated with the TL levels (Table 1) (Leckner, 1978).

\section{Results and discussion}

\subsection{Diurnal and seasonal variation of the Linke's turbidity}

Based on Eqs. (1)-(10), Linke's turbidity values were calculated for hours of clear sky. The average hourly turbidity values with methodologies $\left(T L_{D j}\right.$ and $\left.T L_{L i}\right)$ are shown in Fig. 2 a. The hourly variation of $T L_{D j}$ is similar to that of $\mathrm{TL}_{\mathrm{Li}}$; however, $\mathrm{TL}_{\mathrm{Li}}$ has values on average $10.3 \%$ greater than $\mathrm{TL}_{\mathrm{Dj}}$. The mean deviation of $10.3 \%$ in values of $T L$ is a result of differences between methods and to the integral optical thickness factor and eccentricity correction factor of the Earth's orbit. Variations of TL have also been reported in studies (Li and Lam, 2002; Wen and Yeh, 2009) for Hong Kong and Taichung Harbor, respectively, in the analyses of four models. Turbidity has variability throughout the day, increases in the morning and decreases in the afternoon, with maximum values near solar noon. The maximum values coincide with the period of greatest solar incidence in the day. Therefore, in this analysis, the variability is explained based on the elevation of the radiant flux intensity throughout the day for each hour. Other factors may influence hourly turbidity fluctuation: meteorological conditions, local pollution, water vapor, aerosols that originated from seasonal forest fires, and local industrial activities (Bilbao et al., 2014).

Relative deviation $\left(\mathrm{D}_{\mathrm{TL}}, \%\right)$ was calculated by $\mathrm{D}_{\mathrm{TL}}(\%)=\left[\left(\mathrm{TL}_{\mathrm{h}}-\mathrm{TL}_{\mathrm{m}}\right) /\right.$ $\left.T L_{h}\right] \times 100$, where $\mathrm{TL}_{\mathrm{m}}$ and $\mathrm{TL}_{\mathrm{h}}$ are the values of the total average TL curves and average hourly values, respectively (Fig. 2b). Positive $\mathrm{D}_{\mathrm{TL}}$ values are indicative that the average value is lower than hourly values. $\mathrm{D}_{\mathrm{TL}}$ values for $\mathrm{TL}_{\mathrm{Dj}}$ and $\mathrm{TL}_{\mathrm{Li}}$ varied, respectively, between $-29.82 \%$ and $-26.58 \%$ and between $14.09 \%$ and $17.35 \%$. Considering the time interval from 7:00 a.m. to 4:00 p.m., $\mathrm{D}_{\mathrm{TL}}$ has lower amplitude and shows average value of $\mathrm{D}_{\mathrm{TLDj}}=5.02 \pm 8.69 \%$ and $\mathrm{D}_{\mathrm{TLLi}}=$ $7.89 \% \pm 8.20 \%$. Trabelsi and Masmoudi (2011) pointed out that water vapor in the atmosphere, aerosols, and the variability of the various meteorological variables that influence the atmosphere are crucial in the amplitude of $\mathrm{D}_{\mathrm{TL}}$.

DNI attenuation during the day in the seasons was presented as average values for morning (until 09:30 a.m.), close to solar noon (between 10:30 a.m. and 1:30 p.m.) and afternoon (after 1:30 p.m.) (Fig. 3a, b). For this analysis, all hours of clear sky in the study period were used. The highest degree of DNI transmission is observed in the morning for spring and summer. Close to solar noon, transmission is
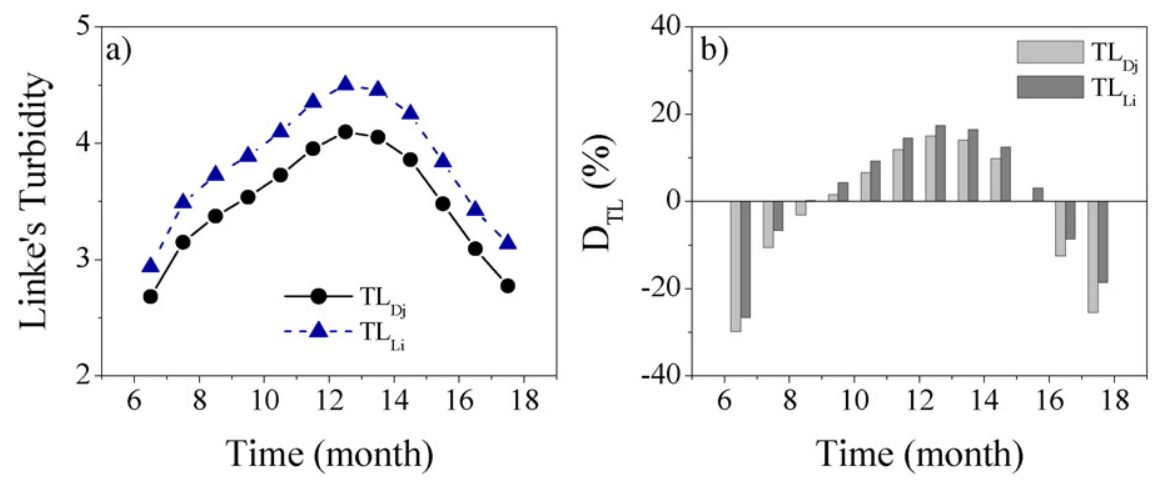

Fig. 2. (a) Average hourly Linke's turbidity variation and (b) deviation for Botucatu from 1996 to 2008.
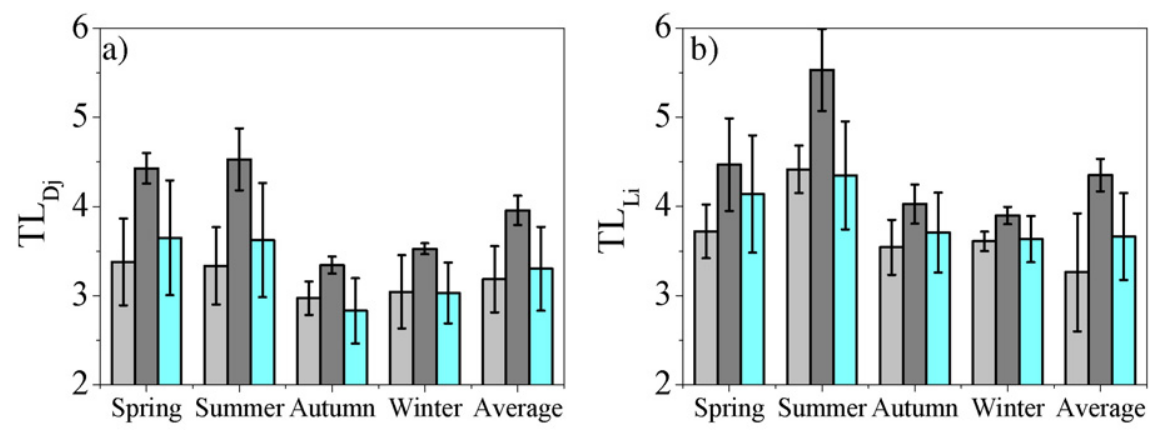

Morning

$\square$ Close to solar noon

Afternoon

Fig. 3. Seasonal variability of the Linke's turbidity in Botucatu from 1996 to 2008. (a) Methodology $\mathrm{TL}_{\mathrm{Dj}}$ and (b) methodology $\mathrm{TL}_{\mathrm{L}}$. 
Table 2

Seasonal variability of the Linke's turbidity in Botucatu from 1996 to 2008

\begin{tabular}{lllll}
\hline & Season & Morning & Close to solar noon & Afternoon \\
\hline $\mathrm{TL}_{\mathrm{Dj}}$ & Spring & $3.38 \pm 0.49$ & $4.43 \pm 0.17$ & $3.65 \pm 0.64$ \\
& Summer & $3.33 \pm 0.43$ & $4.53 \pm 0.35$ & $3.62 \pm 0.64$ \\
& Autumn & $2.97 \pm 0.19$ & $3.34 \pm 0.09$ & $2.83 \pm 0.36$ \\
& Winter & $3.04 \pm 0.41$ & $3.52 \pm 0.06$ & $3.03 \pm 0.34$ \\
& Average & $3.18 \pm 0.37$ & $3.95 \pm 0.16$ & $3.30 \pm 0.47$ \\
$\mathrm{TL}_{\mathrm{Li}}$ & Spring & $3.72 \pm 0.30$ & $4.47 \pm 0.52$ & $4.14 \pm 0.66$ \\
& Summer & $4.41 \pm 0.26$ & $5.53 \pm 0.46$ & $4.35 \pm 0.60$ \\
& Autumn & $3.54 \pm 0.31$ & $4.02 \pm 0.22$ & $3.70 \pm 0.45$ \\
& Winter & $3.61 \pm 0.11$ & $3.89 \pm 0.10$ & $3.63 \pm 0.26$ \\
& Average & $3.26 \pm 0.66$ & $4.35 \pm 0.20$ & $3.66 \pm 0.49$ \\
\hline
\end{tabular}

lower, and consequently, the greater the atmospheric turbidity value. This is related to the optical state of the atmosphere in the seasons. Atmospheric turbidity has different variation in the hot/wet season (spring and summer) and cold/dry (fall and winter), but variation of $\mathrm{TL}_{\mathrm{Dj}}$ (Fig. 3a) is similar to that of $\mathrm{TL}_{\mathrm{Li}}$ (Fig. 3b). Diurnal variability of atmospheric turbidity is evident during the heating phase, while in the cold period, turbidity varied slightly (Uscka-Kowalkowsk, 2013).

Among seasons, atmospheric turbidity has average variability of $\approx 17 \%$. In diurnal evolution, the maximum average value is observed in the summer $\left(\mathrm{TL}_{\mathrm{Dj}}=3.83 \pm 0.62\right)$ and the minimum average value in the autumn $\left(\mathrm{TL}_{\mathrm{Dj}}=3.05 \pm 0.26\right)$. The lowest atmospheric transparency (higher turbidity) occurs in the spring and summer. The $\mathrm{TL}_{\mathrm{Dj}}$ value for spring near solar noon is (4.43 \pm 0.17$)$, and for summer, values are $3.33 \pm 0.43$ and $3.62 \pm 0.64$ in the morning and afternoon, respectively (Table 2). In the diurnal evolution, highest transparency (low turbidity) occurs in the autumn and winter. $\mathrm{TL}_{\mathrm{Li}}$ value for fall in the morning and afternoon is lower than 4 . When compared to values in the morning and afternoon, larger TL values are observed around the solar culmination.

\subsection{Analysis of monthly average Linke's turbidity}

Average monthly turbidity values were obtained from the hourly turbidity values for each month. Average monthly annual evolution of the Linke's turbidity and average values according to the season for $\mathrm{TL}_{\mathrm{Dj}}$ and $\mathrm{TL}_{\mathrm{Li}}$ are shown in Fig. 4(a, b). Atmospheric turbidity values reveal that May and July were the months of the lowest DNI attenuation (high atmospheric transparency), while January was the least transparent month (higher DNI attenuation) (Fig. 4a). Increased atmospheric turbidity is also visible in the months of summer and spring. Between April and August, the atmosphere is less turbid $\left(\mathrm{TL}_{\mathrm{Dj}}\right.$ smaller than 3.46 and $\mathrm{TL}_{\mathrm{LI}}$ smaller than 3.93). Elevation in radiant flux intensity throughout the day has great influence on changes of atmospheric turbidity at different scales, but water vapor and aerosols are the most decisive parameters on seasonal variability.

The period of highest and lowest atmospheric transparency is evident when considering the seasons (Fig. 4b). Most DNI attenuation occurs in spring $\left(\mathrm{TL}_{\mathrm{Dj}}=4.22 \pm 0.05\right.$ and $\left.\mathrm{TL}_{\mathrm{Li}}=4.65 \pm 0.06\right)$ and summer $\left(\mathrm{TL}_{\mathrm{Dj}}=4.27 \pm 0.14\right.$ and $\left.\mathrm{TL}_{\mathrm{Li}}=4.69 \pm 0.15\right)$, months in which the movement of particulate materials that advance to the state of São Paulo with the South Atlantic Frontal Systems (during the spring, especially) and with the South Atlantic Convergence Zone (SACZ) (during the summer) are the highest in the year (Allen et al., 2004). In spring and summer, water vapor content in the atmosphere and the increase in aerosols (Fig. 5a, b) that originated from the burning of biomass (sugarcane, pastures, forests and native forests) for agricultural production and farming in regions near the state of São Paulo and the Amazon region (Holben et al., 2001; França et al., 2014) are the main factors responsible for the increase in atmospheric turbidity and DNI attenuation in Botucatu.

In the summer, increased turbidity is caused mainly by increased water vapor concentration in the atmosphere. Increased turbidity due to atmospheric water vapor and aerosols is also connected to air
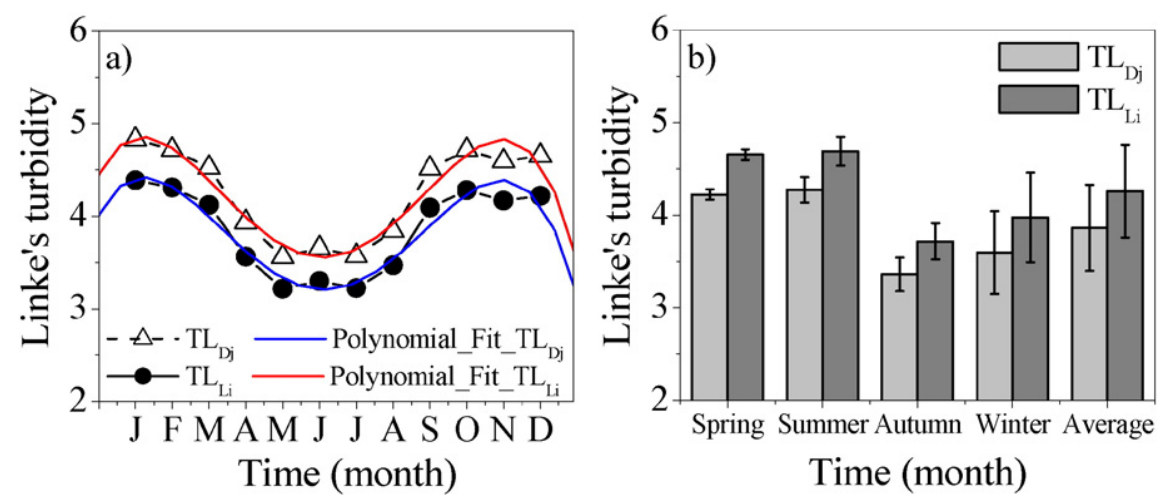

Fig. 4. Variation of the Linke's turbidity in Botucatu from 1996 to 2008. (a) Average annual variation. (b) Average annual variation per season.
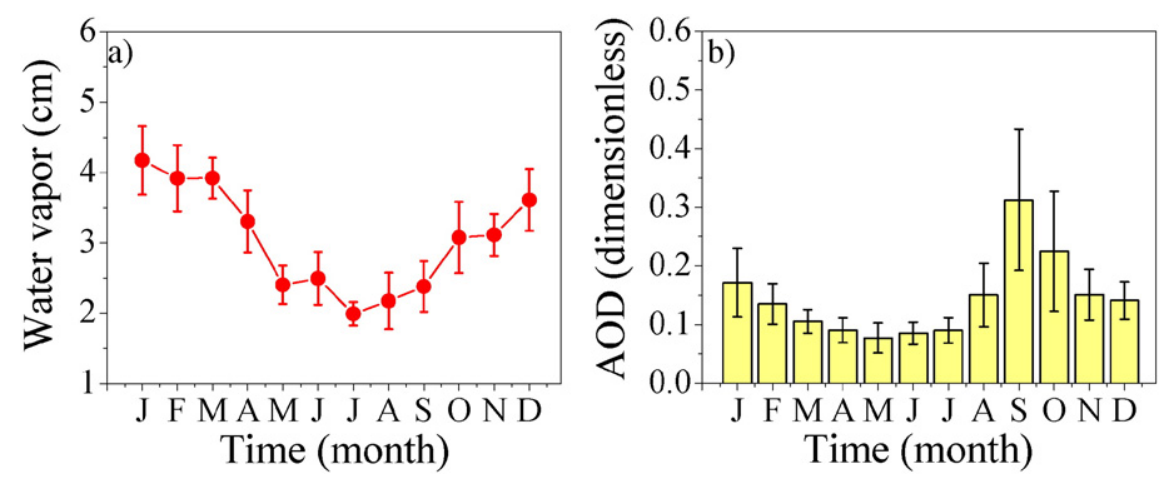

Fig. 5. Average monthly values from 2000 to 2008, considering only days of clear sky. (a) Water vapor and (b) AOD. 
Table 3

Average monthly atmospheric Linke's turbidity with $\mathrm{TL}_{\mathrm{Dj}}$ and $\mathrm{TL}_{\mathrm{Li}}$ for Botucatu from 1996 to 2008 .

\begin{tabular}{|c|c|c|c|c|c|c|c|c|c|c|c|c|c|}
\hline \multicolumn{14}{|c|}{$\underline{\text { Linke's turbidity }\left(\mathrm{TL}_{\mathrm{Dj}}\right)}$} \\
\hline & 1996 & 1997 & 1998 & 1999 & 2000 & 2001 & 2002 & 2003 & 2004 & 2005 & 2006 & 2007 & 2008 \\
\hline $\mathrm{J}$ & - & $3.90 \pm 0.72$ & $4.46 \pm 0.67$ & $4.78 \pm 0.90$ & $4.43 \pm 0.85$ & $4.30 \pm 0.89$ & $4.14 \pm 0.90$ & $4.25 \pm 1.06$ & $4.55 \pm 1.52$ & $4.43 \pm 1.20$ & $4.10 \pm 1.33$ & $4.99 \pm 1.45$ & $4.47 \pm 1.91$ \\
\hline $\mathrm{F}$ & $4.50 \pm 0.77$ & $3.94 \pm 0.63$ & $4.42 \pm 0.87$ & $4.14 \pm 0.93$ & $4.19 \pm 0.91$ & $4.82 \pm 1.43$ & $4.02 \pm 1.36$ & $3.95 \pm 0.78$ & $4.26 \pm 1.07$ & $4.05 \pm 0.86$ & $4.23 \pm 0.99$ & $3.92 \pm 0.81$ & $5.71 \pm 2.07$ \\
\hline M & $4.48 \pm 1.10$ & $3.90 \pm 0.68$ & $4.22 \pm 0.85$ & $3.82 \pm 0.93$ & $4.36 \pm 0.98$ & $4.04 \pm 0.69$ & $3.67 \pm 0.59$ & $4.55 \pm 1.59$ & $3.94 \pm 0.70$ & $3.94 \pm 0.76$ & $4.15 \pm 0.85$ & $4.37 \pm 1.74$ & $4.35 \pm 1.27$ \\
\hline A & $3.64 \pm 0.61$ & $3.45 \pm 0.73$ & $3.41 \pm 0.86$ & $3.44 \pm 0.62$ & $3.21 \pm 0.51$ & $3.50 \pm 0.84$ & $3.44 \pm 0.51$ & $4.16 \pm 2.18$ & $3.92 \pm 1.20$ & $4.05 \pm 0.76$ & $3.06 \pm 0.49$ & $3.80 \pm 0.75$ & $3.57 \pm 0.98$ \\
\hline M & $3.33 \pm 0.53$ & $3.17 \pm 0.61$ & $2.98 \pm 0.56$ & $3.14 \pm 0.79$ & $3.31 \pm 0.77$ & $3.32 \pm 1.16$ & $3.23 \pm 1.11$ & $2.99 \pm 0.63$ & $3.16 \pm 0.59$ & $3.56 \pm 1.04$ & $2.98 \pm 0.50$ & $3.57 \pm 1.11$ & $3.19 \pm 0.61$ \\
\hline $\mathrm{J}$ & $3.56 \pm 1.49$ & $3.03 \pm 0.76$ & $3.28 \pm 0.80$ & $2.97 \pm 0.51$ & $3.60 \pm 0.81$ & $3.78 \pm 1.23$ & $3.10 \pm 0.51$ & $3.38 \pm 1.07$ & $3.51 \pm 1.13$ & $3.33 \pm 0.84$ & $3.04 \pm 0.60$ & $3.09 \pm 0.71$ & $3.21 \pm 0.66$ \\
\hline $\mathrm{J}$ & $3.21 \pm 0.63$ & $3.41 \pm 0.73$ & $3.58 \pm 0.73$ & $3.36 \pm 0.82$ & $3.09 \pm 0.75$ & $3.34 \pm 0.91$ & $2.96 \pm 0.77$ & $3.18 \pm 0.52$ & $3.32 \pm 0.78$ & $3.06 \pm 0.69$ & $3.26 \pm 0.70$ & $3.01 \pm 0.64$ & $3.03 \pm 0.76$ \\
\hline A & $3.50 \pm 0.99$ & $2.84 \pm 0.51$ & $4.57 \pm 0.72$ & $3.60 \pm 0.83$ & $3.44 \pm 0.72$ & $3.55 \pm 0.83$ & $3.73 \pm 0.89$ & $3.27 \pm 0.86$ & $3.18 \pm 0.98$ & $3.64 \pm 1.04$ & $3.53 \pm 0.78$ & $3.11 \pm 0.64$ & $3.31 \pm 0.64$ \\
\hline $\mathrm{S}$ & $4.03 \pm 1.00$ & $4.20 \pm 0.85$ & $4.59 \pm 1.16$ & $4.30 \pm 0.88$ & $3.98 \pm 0.42$ & $4.20 \pm 1.33$ & $4.48 \pm 1.03$ & $3.64 \pm 0.85$ & $4.47 \pm 0.92$ & $4.28 \pm 1.39$ & $3.64 \pm 0.69$ & $3.88 \pm 0.81$ & $3.84 \pm 1.01$ \\
\hline 0 & $4.09 \pm 0.67$ & $3.04 \pm 0.00$ & $4.12 \pm 0.83$ & $4.24 \pm 0.96$ & $4.52 \pm 0.97$ & $4.54 \pm 1.86$ & $4.74 \pm 0.59$ & $3.77 \pm 0.99$ & $3.69 \pm 0.86$ & $4.53 \pm 0.74$ & $4.20 \pm 0.93$ & $4.36 \pm 0.70$ & $4.40 \pm 0.69$ \\
\hline $\mathrm{N}$ & $3.56 \pm 0.66$ & - & $3.90 \pm 0.57$ & $4.00 \pm 0.81$ & $4.34 \pm 1.12$ & $5.70 \pm 1.18$ & $4.17 \pm 0.96$ & $4.18 \pm 1.10$ & $4.01 \pm 0.84$ & $3.90 \pm 0.75$ & $4.12 \pm 0.96$ & $3.89 \pm 0.99$ & $4.10 \pm 0.65$ \\
\hline D & $4.56 \pm 0.82$ & - & $4.31 \pm 0.69$ & $4.45 \pm 0.99$ & $4.51 \pm 0.90$ & $3.88 \pm 1.35$ & $3.79 \pm 0.71$ & $4.39 \pm 0.77$ & $4.43 \pm 0.90$ & $4.20 \pm 0.92$ & $4.13 \pm 0.68$ & $4.22 \pm 1.37$ & $3.87 \pm 0.85$ \\
\hline Average & $3.86 \pm 0.84$ & $3.49 \pm 0.62$ & $3.99 \pm 0.78$ & $3.85 \pm 0.83$ & $3.91 \pm 0.81$ & $4.08 \pm 1.14$ & $3.79 \pm 0.83$ & $3.81 \pm 1.03$ & $3.87 \pm 0.96$ & $3.92 \pm 0.92$ & $3.70 \pm 0.79$ & $3.85 \pm 0.98$ & $3.92 \pm 1.01$ \\
\hline \multicolumn{14}{|c|}{ Linke's turbidity $\left(\mathrm{TL}_{\mathrm{Li}}\right)$} \\
\hline & 1996 & 1997 & 1998 & 1999 & 2000 & 2001 & 2002 & 2003 & 2004 & 2005 & 2006 & 2007 & 2008 \\
\hline $\mathrm{J}$ & - & $4.32 \pm 0.79$ & $4.94 \pm 0.74$ & $5.29 \pm 0.99$ & $4.90 \pm 0.94$ & $4.76 \pm 0.98$ & $4.58 \pm 0.99$ & $4.70 \pm 1.17$ & $4.99 \pm 1.59$ & $4.72 \pm 1.50$ & $4.54 \pm 1.48$ & $5.51 \pm 1.60$ & $4.69 \pm 2.07$ \\
\hline $\mathrm{F}$ & $4.84 \pm 0.83$ & $4.36 \pm 0.70$ & $4.88 \pm 0.96$ & $4.58 \pm 1.02$ & $4.64 \pm 1.01$ & $5.24 \pm 1.39$ & $4.46 \pm 1.50$ & $4.37 \pm 0.86$ & $4.71 \pm 1.18$ & $4.48 \pm 0.95$ & $4.68 \pm 1.09$ & $4.34 \pm 0.89$ & $5.86 \pm 1.81$ \\
\hline M & $4.90 \pm 1.20$ & $4.31 \pm 0.74$ & $4.67 \pm 0.94$ & $4.23 \pm 1.03$ & $4.83 \pm 1.08$ & $4.47 \pm 0.76$ & $4.06 \pm 0.65$ & $5.02 \pm 1.76$ & $4.36 \pm 0.77$ & $4.36 \pm 0.83$ & $4.47 \pm 0.69$ & $4.83 \pm 1.91$ & $4.55 \pm 1.04$ \\
\hline A & $4.08 \pm 0.66$ & $3.79 \pm 0.71$ & $3.77 \pm 0.97$ & $3.81 \pm 0.69$ & $3.55 \pm 0.57$ & $3.88 \pm 0.93$ & $3.81 \pm 0.57$ & $4.50 \pm 2.30$ & $4.34 \pm 1.33$ & $4.49 \pm 0.85$ & $3.39 \pm 0.54$ & $4.20 \pm 0.83$ & $3.95 \pm 1.09$ \\
\hline M & $3.83 \pm 0.59$ & $3.52 \pm 0.67$ & $3.30 \pm 0.62$ & $3.47 \pm 0.89$ & $3.63 \pm 0.89$ & $3.67 \pm 1.30$ & $3.57 \pm 1.24$ & $3.25 \pm 0.74$ & $3.49 \pm 0.65$ & $3.95 \pm 1.15$ & $3.30 \pm 0.56$ & $3.96 \pm 1.23$ & $3.49 \pm 0.69$ \\
\hline J & $4.10 \pm 1.58$ & $3.34 \pm 0.84$ & $3.64 \pm 0.88$ & $3.29 \pm 0.56$ & $3.97 \pm 0.93$ & $4.17 \pm 1.37$ & $3.44 \pm 0.57$ & $3.75 \pm 1.19$ & $3.84 \pm 1.30$ & $3.69 \pm 0.93$ & $3.35 \pm 0.69$ & $3.37 \pm 0.82$ & $3.55 \pm 0.75$ \\
\hline J & $3.73 \pm 0.71$ & $3.78 \pm 0.81$ & $3.95 \pm 0.83$ & $3.72 \pm 0.91$ & $3.30 \pm 0.83$ & $3.62 \pm 0.83$ & $3.26 \pm 0.86$ & $3.52 \pm 0.57$ & $3.68 \pm 0.86$ & $3.40 \pm 0.76$ & $3.61 \pm 0.77$ & $3.34 \pm 0.71$ & $3.35 \pm 0.84$ \\
\hline A & $4.00 \pm 1.11$ & $3.15 \pm 0.57$ & $5.06 \pm 0.79$ & $3.99 \pm 0.92$ & $3.81 \pm 0.80$ & $3.93 \pm 0.91$ & $4.14 \pm 0.98$ & $3.59 \pm 0.99$ & $3.52 \pm 1.09$ & $4.03 \pm 1.16$ & $3.88 \pm 0.88$ & $3.44 \pm 0.71$ & $3.58 \pm 0.62$ \\
\hline $\mathrm{S}$ & $4.50 \pm 1.09$ & $4.65 \pm 0.94$ & $5.08 \pm 1.28$ & $4.76 \pm 0.97$ & $4.36 \pm 0.50$ & $4.65 \pm 1.48$ & $4.87 \pm 1.09$ & $4.02 \pm 0.95$ & $4.83 \pm 0.84$ & $4.72 \pm 1.55$ & $4.03 \pm 0.77$ & $4.29 \pm 0.89$ & $4.25 \pm 1.11$ \\
\hline 0 & $4.46 \pm 0.74$ & $3.36 \pm 0.00$ & $4.56 \pm 0.92$ & $4.69 \pm 1.06$ & $4.89 \pm 0.96$ & $5.01 \pm 2.06$ & $5.24 \pm 0.65$ & $4.17 \pm 1.09$ & $4.09 \pm 0.96$ & $5.02 \pm 0.81$ & $4.61 \pm 0.98$ & $4.82 \pm 0.77$ & $4.87 \pm 0.76$ \\
\hline $\mathrm{N}$ & $3.77 \pm 0.72$ & - & $4.31 \pm 0.63$ & $4.43 \pm 0.89$ & $4.80 \pm 1.23$ & $6.30 \pm 1.31$ & $4.61 \pm 1.06$ & $4.62 \pm 1.21$ & $4.44 \pm 0.92$ & $4.26 \pm 0.90$ & $4.55 \pm 1.05$ & $4.30 \pm 1.09$ & $4.54 \pm 0.72$ \\
\hline D & $4.83 \pm 0.89$ & - & $4.77 \pm 0.77$ & $4.92 \pm 1.09$ & $4.99 \pm 0.99$ & $4.30 \pm 1.49$ & $4.20 \pm 0.78$ & $4.86 \pm 0.85$ & $4.88 \pm 1.01$ & $4.65 \pm 1.01$ & $4.57 \pm 0.75$ & $4.67 \pm 1.51$ & $4.28 \pm 0.94$ \\
\hline Average & $4.28 \pm 0.92$ & $3.86 \pm 0.68$ & $4.41 \pm 0.86$ & $4.26 \pm 0.92$ & $4.31 \pm 0.89$ & $4.50 \pm 1.23$ & $4.19 \pm 0.91$ & $4.20 \pm 1.14$ & $4.27 \pm 1.04$ & $4.31 \pm 1.03$ & $4.08 \pm 0.85$ & $4.26 \pm 1.08$ & $4.25 \pm 1.04$ \\
\hline
\end{tabular}


circulation, which is important for transporting air masses and the temporal variation of turbidity (Elminir et al., 2006, de Freitas et al., 2005). In the cold season (autumn and winter), days with low rainfall, the atmosphere is frequently lighter with lower concentrations of water vapor and aerosols in the local atmosphere. The seasonal variability of atmospheric turbidity described in the literature (Grenier et al., 1995; Power and Goyal, 2003; Uscka-Kowalkowsk, 2013), as observed in Botucatu/SP, shows maximum values in spring and summer and minimum values in autumn and winter.

Average monthly annual turbidity values show low variation among the 13 studied years (Table 3$)$, with maximum $T L_{D j}$ values $(5.70 \pm$ $1.18)$ in October 2001 and minimum value of $(2.84 \pm 0.51)$ in August 1997. Minimum $\mathrm{TL}_{\mathrm{Li}}$ value $(3.15 \pm 0.57)$ was recorded in August 1997 and maximum $(6.30 \pm 1.31)$ in October 2001 . $\mathrm{TL}_{\mathrm{LI}}$ values were $9.31 \%$ higher than $\mathrm{TL}_{\mathrm{Dj}}$ values, and this difference may be related to the equations used. Turbidity indicated growing trend, and this effect may be due to increased burning (illegal deforestation in the Amazon rainforest and fires), increased urbanization and local, and regional industrial expansion. Depending on the location, urbanization is the main factor responsible for increased pollution and atmospheric turbidity in major regions (Rahoma and Hassan, 2012). Turbidity indexes obtained for Botucatu are similar to those found for 3 regions of Bangladesh, TL between 3.46 and 4.83 (Hussain et al., 2000) and in places in Africa $(\mathrm{TL}=3.50)$ (Diabaté et al., 2003). Atmospheric turbidity with $\mathrm{TL}_{\mathrm{Dj}}$ and $\mathrm{TL}_{\mathrm{Li}}$ are lower than those obtained in Hong Kong, TL between 3.70 and 5.26 (Li and Lam, 2002). Despite these results, each site has different characteristics and weather conditions; consequently, different turbidity levels are found.

\subsection{Comparisons of TL calculated in Botucatu with those available on the SoDA Website}

Inserting latitude, longitude, and altitude of the place of interest, it is possible to obtain the monthly Linke's turbidity using global maps for any place in the world via SoDA website (www.soda-is.com). Linke's turbidity $\left(\mathrm{TL}_{\mathrm{SoDA}}\right.$ ) is based on a series of global data from satellites, water vapor, aerosols, and from information on turbidity on the surface (Hove and Manyumbu, 2013). Monthly TL values (Table 4) available on SoDA are higher in spring/summer and lower in autumn/winter; this seasonality resembles those obtained in this work with $\mathrm{TL}_{\mathrm{Dj}}$ and $\mathrm{TL}_{\mathrm{Li}}$, corroborating higher atmospheric transparency in autumn/winter and lower in spring/summer. The atmospheric turbidity calculated by $\mathrm{TL}_{\mathrm{Dj}}$ and $\mathrm{TL}_{\mathrm{LI}}$ is, respectively, $15.80 \%$ and $23.52 \%$ greater than that $\mathrm{TL}_{\mathrm{SoDA}}$. The variation coefficient $(\mathrm{vc})$ expressed as percentage is indicative of data dispersion and was used in this study. $\mathrm{TL}_{\mathrm{Dj}}$ has $\mathrm{vc}=12.04 \%, \mathrm{TL}_{\mathrm{Li}}$ has $\mathrm{vc}=11.76 \%$, and $\mathrm{TL}_{\text {SoDA }}$ has variation coefficient equal to $9.66 \%$. Estimates with satellites are subject to larger errors, and then the results obtained in this study are more representative because they have been determined with surface measures. However, the estimates provided by SoDA cannot be disregarded.

Monthly changes can be observed considering the modulation of the observed profile. The amplitude of the turbidity variation is calculated by: $[\mathrm{TL}(\max )-\mathrm{TL}(\min )] /[\mathrm{TL}(\max )+\mathrm{TL}(\min )]$. Based on local data, modulation with $\mathrm{TL}_{\mathrm{Dj}}$ and $\mathrm{TL}_{\mathrm{Li}}$ was 15.41 and $15.14 \%$, respectively. Using the $\mathrm{TL}_{\mathrm{SoDA}}$ results, modulation is $13.84 \%$. On Crete Island, modulation was 18\% (Mavromatakis and Franghiadakis, 2007).

Table 4

Linke's turbidity available on SoDA (www.soda-is.com).

\begin{tabular}{lllllllllllll} 
Month & Jan & Feb & Mar & Apr & May & Jun & Jul & Aug & Sep & Oct & Nov & Dec \\
\hline TL $_{\text {SoDA }}$ & 3.40 & 3.70 & 3.70 & 3.60 & 3.30 & 3.10 & 2.80 & 2.80 & 3.40 & 3.00 & 3.20 & 3.10 \\
\hline
\end{tabular}

\subsection{Polynomial correlations for the Linke's turbidity}

Fig. 4 shows that fourth-degree polynomial models have been adjusted for the temporal variation of $\mathrm{TL}_{\mathrm{Dj}}$ and $\mathrm{TL}_{\mathrm{LI}}$, respectively (Eqs. (11) and (12)), and shows how the variability occurs for every month throughout the year. This polynomial degree was chosen for presenting high correlation coefficient and lower error. The coefficients depend on the month of the year as input. The main application of this polynomial regression is in filling some gaps in the number of local data or regions with similar climatic conditions.

$T L_{D j}=4.03+0.71 \times T-0.38 \times T^{2}+0.05 \times T^{3}-0.002 \times T^{4}$
$T L_{L i}=4.47+0.72 \times T-0.39 \times T^{2}+0.06 \times T^{3}-0.002 \times T^{4}$

Determination coefficients were high and equal $\left(R^{2}=0.88\right)$. This result shows that there is good relationship between monthly turbidity variation and months of the year in Botucatu. The polynomial equations enable determination of monthly TL values (in the hourly partition of DNI) with high correlation coefficient (0.94); therefore, the average monthly atmospheric turbidity can be obtained. In 28 locations in Italy, a study by Cucumo et al. (2000) generated eighth-grade polynomial equations with error of $\pm 5 \%$. The present results are according to those found for the Ghardaia region, province of Algeria, in which sixth-grade polynomial equations as a function of the years were adjusted (Djafer and Irbah, 2013).

\subsection{Relationship between Linke's turbidity and meteorological parameters}

Atmospheric turbidity depends on the short-term variation of local weather conditions (air temperature, wind speed, and direction) and long-term climate variability (Chaâbane et al., 2004). Wind (speed and direction), for example, can carry enough moisture and suspended particulate material in the air (aerosols) from distant sources and play an important role in spatial and temporal variation of the atmospheric turbidity (Masmoudi et al., 2003). Therefore, the influence of the average wind speed on the Linke's turbidity in Botucatu was analyzed.

The atmospheric turbidity in Botucatu increases with increasing wind speed (Fig. 6a). Intervals of $0.40 \mathrm{~m} / \mathrm{s}$ were separated for the wind speed in order to better analyze the temporal variability. In this study, wind speed ranged from 3.40 to $7.40 \mathrm{~m} / \mathrm{s}$, with maximum values prevailing in the spring. For wind speed values lower than $5.0 \mathrm{~m} / \mathrm{s}$, the average turbidity is $\mathrm{TL}_{\mathrm{Dj}}=3.92 \pm 0.54$ and $\mathrm{TL}_{\mathrm{Li}}=4.32 \pm 0.58$. When the wind speed reaches average value of $7.40 \mathrm{~m} / \mathrm{s}$, TL can reach average values equal to $\mathrm{TL}_{\mathrm{Dj}}=4.51 \pm 0.58$ and $\mathrm{TL}_{\mathrm{Li}}=4.97 \pm 0.27$. These results are characteristic of local effects, both climatic conditions and human influence.

The influence of wind speed was analyzed as a function of the turbidity variation interval. With wind speed $\geq 5.0 \mathrm{~m} / \mathrm{s}$, it was found $8.59 \%$ of turbidity with $\mathrm{TL}_{\mathrm{Dj}}$ values $\geq 4.50$. When $\mathrm{TL}_{\mathrm{Li}}<5.0,73.54 \%$ of the observations are for wind speed between 3.0 and $5.0 \mathrm{~m} / \mathrm{s}$. In the results of this study, wind speed was positively correlated with atmospheric turbidity with $r=0.355$ for $\mathrm{TL}_{\mathrm{Dj}}$ and $r=0.353$ for $\mathrm{TL}_{\mathrm{Li}}$. Atmospheric turbidity can correlate positively or negatively with wind. In Cairo, Egypt, for example, atmospheric turbidity decreases with increasing wind speed, Elminir et al. (2006), which can be explained by the air flux caused by buildings.

Fig. $6 \mathrm{~b}$ shows the variation of the Linke's turbidity $\mathrm{TL}_{\mathrm{Dj}}$ and $\mathrm{TL}_{\mathrm{Li}}$ according to air temperature. Similarly to wind speed, air temperature is of utmost importance in climate studies, as it varies in space, time, and altitude. Thus, it is possible to analyze turbidity variability with air temperatures in the range $\left[15.50-24.50{ }^{\circ} \mathrm{C}\right]$ at $0.50{ }^{\circ} \mathrm{C}$ interval. $\mathrm{TL}$ increases linearly with the air temperature. The minimum turbidity value $\left(\mathrm{TL}_{\mathrm{Dj}}=2.81 \pm 0\right.$ and $\left.\mathrm{TL}_{\mathrm{Li}}=3.10 \pm 0\right)$ occurs when the average air temperature is $15.50{ }^{\circ} \mathrm{C}$ and maximum $\left(\mathrm{TL}_{\mathrm{Dj}}=4.14 \pm 0.29\right.$ and $\mathrm{TL}_{\mathrm{Li}}=4.57 \pm 0.32$ ) when the air temperature is $24.5^{\circ} \mathrm{C}$. The lowest 

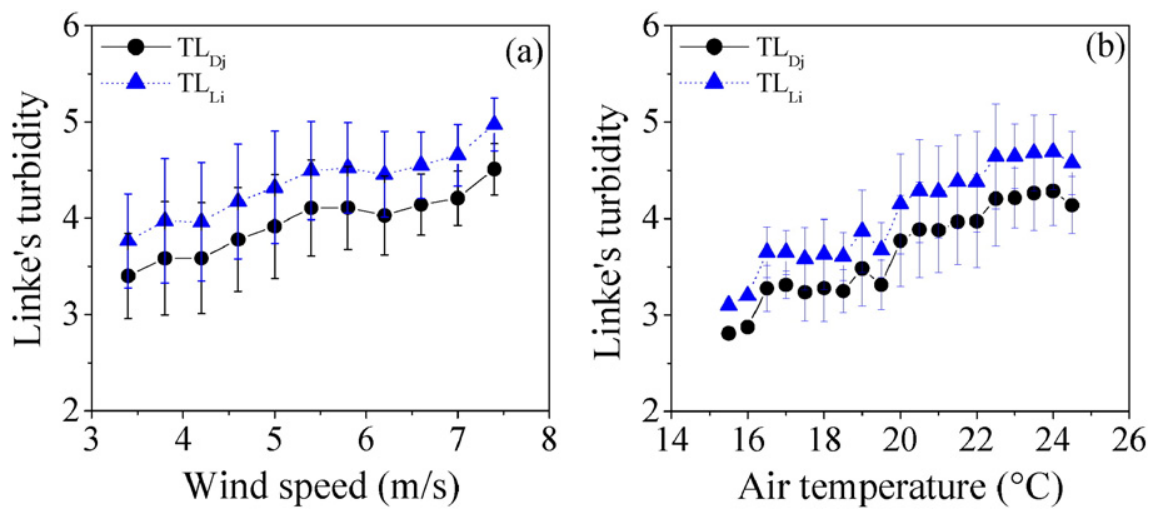

Fig. 6. Variation of $\mathrm{TL}_{\mathrm{Dj}}$ and $\mathrm{TL}_{\mathrm{Li}}$ as a function of (a) wind speed and (b) air temperature.

values occur primarily in the winter (low temperatures and dry atmosphere).

When the average air temperature is equal to $19.50^{\circ} \mathrm{C}$, a decrease in turbidity is observed, which is associated with the frequency of days in the autumn and winter, where the atmosphere was clear with Linke's turbidity values predominantly lower than 3.50. The air temperature correlates positively with atmospheric turbidity with $r=0.71$ for $\mathrm{TL}_{\mathrm{Dj}}$ and $r=0.70$ for $\mathrm{TL}_{\mathrm{Li}}$. These results confirm the influence of wind speed and air temperature on temporal variability of the atmospheric turbidity in the study site.

\subsection{Linke's turbidity frequency distribution}

The frequency distribution in the atmospheric turbidity classification is an important indicator in the characterization of predominant classes in the considered variation intervals. The frequency of occurrence and the cumulative frequency of $T L_{D j}$ and $T L_{L i}$ are seen in (Fig. 7a, b), respectively. Frequency distribution was separated in the range from 1.95 to 12.00 with interval of 0.30 . About $20,124 \mathrm{~h}$ of clear sky were used. Fig. 7(a) shows a modal distribution with maximum of 2.85 for $\mathrm{TL}_{\mathrm{Dj}}$ and 3.15 for $\mathrm{TL}_{\mathrm{Li}}$, representing $16.07 \%$ and $14.59 \%$ of observations, respectively. The lowest value is observed for TL equal to 12 . For $\mathrm{TL}_{\mathrm{Li}}$, about $92.06 \%$ of occurrences are in the range of [2.0-6.0] and $93.95 \%$ of occurrences of this range for $\mathrm{TL}_{\mathrm{Dj}}$. Analyzing four techniques for TL calculation, Wen and Yeh (2009) observed different variations as follows: [0.5 to 7.0] methodology 1 ; [2.0-10.0] methodology 2; [4.0-10] methodology 3; [5.0-10.0] methodology 4, with values inclined towards the left and peak between 5 and 8 .

The cumulative frequency of the hourly turbidity distribution (Fig. 7b) serves as an indicator of the percentage of observations (clear sky hours) in which a given turbidity level is reached. The results show that when $T L_{D j} \leq 2.0 \%, \approx 41.83$ h of clear sky occurred, representing a pure, clear and warm air Rayleigh atmosphere. Value of $\approx 30.50 \%$ of clear sky hours are in the range $\left(2.0<\mathrm{TL}_{\mathrm{Dj}} \leq 4.0\right)$, which shows a cloudy, moist and warm air atmosphere. About $\approx 28.12 \%$ of hours, calculated turbidity exceeded 4.0 , representing a polluted atmosphere. When compared with $\mathrm{TL}_{\mathrm{Dj}}$, turbidity with $\mathrm{TL}_{\mathrm{Li}}$ has $15.10 \%$ reduction in pure, clear, and hot air Rayleigh atmosphere condition; 5.82\% increase in turbid, moist, and hot air atmosphere; and $9.28 \%$ increase in polluted atmosphere.

\section{Conclusions}

This study calculates DNI extinction in the region of Botucatu for hourly and average monthly values. DNI extinction is given by the Linke's atmospheric turbidity. $\mathrm{TL}_{\mathrm{Dj}}$ and $\mathrm{TL}_{\mathrm{Li}}$ methodologies were adopted. Turbidity has variability throughout the day, increases in the morning and decreases in the afternoon, with maximum values near solar noon. Hourly turbidity with $\mathrm{TL}_{\mathrm{LI}}$ calculates $10.34 \%$ greater values than $T L_{D j}$. Daytime average hourly variability of TL is intensified by increasing the radiant flux intensity. For annual daily variability in spring and summer, water vapor in the atmosphere and aerosols are the main factors responsible for increased atmospheric turbidity. In the summer, increased turbidity is mainly caused by increased water vapor in the atmosphere.

When related to meteorological variables, turbidity increases with increasing wind speed and air temperature, i.e., positively correlated with atmospheric turbidity. The highest occurrences of turbid atmosphere and warm air were in the spring and summer, periods with lower atmospheric transparency. In approximately $\approx 28.12 \%$ of the analyzed hours, the turbidity obtained exceeded the value of 4.0 , representing a polluted atmosphere.

Increasing fires, growing urbanization, and local and regional industrial expansion are responsible for the increasing turbidity trend.
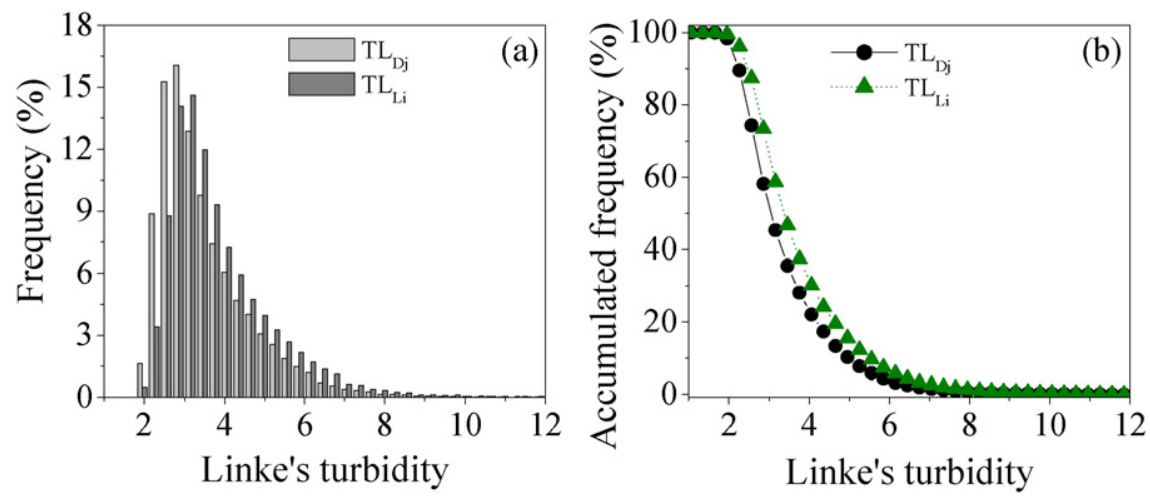

Fig. 7. Atmospheric turbidity $\mathrm{TL}_{\mathrm{Dj}}$ and $\mathrm{TL}_{\mathrm{Li}}$ from 1996 and 2008. (a) Hourly frequency distribution and (b) hourly accumulated frequency. 
In Brazil, burning of native forests for agricultural production and cattle ranching in the Amazon rainforest region, as well as agricultural burning and sugarcane burning in regions near Botucatu, are great villains in increasing particulate matter in the atmosphere. In the southeastern region of Brazil, due to atmospheric circulation, these events alter the atmosphere pattern. In the summer, air circulation is also responsible for carrying enough moisture from the Amazon region to southeastern Brazil. Therefore, the atmosphere of Botucatu seems to be influenced by aerosols and water vapor from different origins. These two parameters alter the DNI distribution in the atmosphere and are critical in the radiant flux density on the surface.

There is a state law in São Paulo establishing a reduction in the practice of sugarcane burning; however, the solid residue from crushed sugarcane (bagasse) is used as renewable industrial fuel, so the biomass combustion emissions probably have not reduced (Scaramboni et al., 2015). This paper shows that the effect on the study period is significant, and environmental public policies should be considered.

Therefore, with deforestation of native forests and increasing urbanization, further studies should be carried out in order to analyze new standards in the atmosphere and in DNI distribution. Further studies have become indispensable because recent studies have shown that accidental and intentional fires have increased. These fires occur mainly in the states of the Amazon rainforest region and cause air pollution with damages to health of millions of people and to aviation.

\section{Acknowledgments}

This work was supported by CAPES, CNPq and FAPESP. We also acknowledge associated NASA personnel for the production of data used in this research and SoDA website.

\section{References}

Allen, A.G., Cardoso, A.A., Da Rocha, G.O., 2004. Influence of sugar cane burning on aerosol soluble íon composition in Southeastern Brazil. Atmos. Environ. 38, 5025-5038.

Batlles, F.J., Rubio, M.A., Tovar, J., et al., 2000. Empirical modeling of hourly direct irradiance by means of hourly global irradiance. Energy 25, 675-688.

Bertin, A., Frangi, J.P., 2013. Contribution to the study of the wind and solar radiation over Guadeloupe. Energy Convers. Manag. 75, 593-602.

Bilbao, J., Román, R., Miguel, A., 2014. Turbidity coefficients from normal direct solar irradiance in central Spain. Atmos. Res. 143, 73-84 (2014).

Cañada, J., Pinazo, J.M., Boscá, J.V., 1993. Determination of Ångström's turbidity coefficient at Valencia. Renew. Energy 3, 621-626.

Chaâbane, M., Masmoudi, M., Medhioub, K., 2004. Determination of Linke turbidity factor from solar radiation measurement in northern Tunisia. Renew. Energy 29 2065-2076.

Chaiwiwatworakul, P., Chirarattananon, S., 2004. An investigation of atmospheric turbidity of Thai sky. Energy Build. 36, 650-659.

Codato, G., Oliveira, A.P., Soares, J., et al., 2008. Global and diffuse solar irradiances in urban and rural areas in southeast Brazil. Theor. Appl. Climatol. 93, 57-73.

CPA, 2016. Clima dos Municípios Paulistas. Disponivel em http://www.cpa.unicamp.br/ outras-informacoes/clima_muni_086.html (Acesso em $<17 / 06 / 2016>$. [In portuguese]).

Cucumo, M., Kaliakatsos, D., Marinelli, V., 2000. A calculation method for the estimation of the Linke turbidity factor. Renew. Energy 19, 249-258.

Dal Pai, A., Escobedo, J.F., Dal Pai, E., et al., 2014. Estimation of hourly, daily and monthly mean diffuse radiation based on MEO shadowring correction. Energy Procedia 57, 1150-1159.

Diabaté, L., Remund, J., Wald, L., 2003. Linke turbidity factors for several sites in Africa. Sol. Energy 75, 111-119.

Djafer, D., Irbah, A., 2013. Estimation of atmospheric turbidity over Ghardaïa city. Atmos. Res. 128, 76-84.

Dos Santos, C.M., Souza, J.L., Ferreira Junior, R.A., et al., 2014. On modeling global solar irradiation using air temperature for Alagoas State, Northeastern Brazil. Energy 71, 388-398.

Ellouz, F., Masmoudi, M., Medhioub, K., 2013. Study of the atmospheric turbidity over Northern Tunisia. Renew. Energy 51, 513-517.

El-Metwally, M., 2013. Indirect determination of broadband turbidity coefficients over Egypt. Meteorog. Atmos. Phys. 119, 71-90.

Elminir, K.H., Hamid, R.H., El-Hussainy, F., et al., 2006. The relative influence of the anthropogenic air pollutants on the atmospheric turbidity factors measured at an urban monitoring station. Sci. Total Environ. 368, 732-743.

Eltbaakh, Y.A., Ruslan, M.H., Alghoul, M.A., et al., 2012. Issues concerning atmospheric turbidity indices. Renew. Sust. Energ. Rev. 16, 285-6294.

Escobedo, J.F., Gomes, E.N., Oliveira, A.P., et al., 2011. Ratios of UV, PAR and NIR components to global solar radiation measured at Botucatu site in Brazil. Renew. Energy 36, 169-178.

Flores, J.L., Karam, H.A., Filho, E.P.M., et al., 2015. Estimation of atmospheric turbidity and surface radiative parameters using broadband clear sky solar irradiance models in Rio de Janeiro-Brasil. Theor. Appl. Climatol. http://dx.doi.org/10.1007/s00704014-1369-7.

Formenti, P., Winkler, H., Fourie, P., et al., 2002. Aerosol optical depth over a remote semiarid region of South Africa from spectral measurements of the daytime solar extinc tion and the nighttime stellar extinction. Atmos. Res. 62, 11-32.

Franç, D., Longo, K., Rudorff, B., et al., 2014. Pre-harvest sugarne burning emission inventories based on remote sensing data in the state of state of São Paulo, Brazil. Atmos. Environ. 99, 446-456.

Freitas, S.R., Longo, K.M., Dias, M.A.F.S., et al., 2005. Monitoring the transport of biomass burning emissions in South America. Environ. Fluid Mech. 5, 135-167.

Gao, B.C., Kaufman, Y.J., 2003. Water vapour retrievals using moderate resolution imaging spectroradiometer (MODIS) near-infrared channels. J. Geophys. Res. 108 (D13), 4389 http://dx.doi.org/10.1029/2002JD003023.

Grenier, J.C., de La Casinière, A., Cabot, T., 1995. Atmospheric turbidity analyzed by means of standardized Linke's turbidity factor. J. Appl. Meteorol. 34, 1449-1458.

Gueymard, C.A., 2012. Temporal variability in direct and global irradiance at various time scales as affected by aerosols. Sol. Energy 86, 3544-3553.

Holben, B.N., et al., 2001. An emerging ground-based aerosol climatology: aerosol optical depth from AERONET. J. Geophys. Res. 106 (11), 12.067-12.097.

Hove, T., Manyumbu, E., 2013. Estimates of the Linke turbidity factor over Zimbabwe using ground-measured clear-sky global solar radiation and sunshine records based on a modified ESRA clear-sky model approach. Renew. Energy 52, 190-196.

Hussain, M., Khatun, S., Rasul, M.G., 2000. Determination of atmospheric turbidity in Bangladesh. Renew. Energy 20, 325-332.

IBGE, 2015. Diretoria de Pesquisas-DPE-Coordenação de População e Indicadores Sociais-COPIS. 2014. Acesso em: <10/12/2015>. Disponível em http://cod.ibge.gov. br/2378L.

Inman, R.H., Edson, J.G., Coimbra, C.F.M., 2015. Impact of local broadband turbidity estimation on forecasting of clear sky direct normal irradiance. Sol. Energy 117, 125-138.

Iqbal, M., 1983. An Introduction to Solar Radiation. Academic Press, New York, p. 390.

Jones, C., Carvalho, L.M.V., Higgins, R.W., et al., 2004. Climatology of tropical intraseasonal convective anomalies: 1979-2002. J. Clim. 17, 523-539.

Karayel, M., Navvab, M., Ne'eman, E., et al., 1984. Zenith luminance and sky luminance distributions for daylighting calculations. Energy Build. 6 (3), 283-291.

Kasten, F., 1980. A simple parameterization of the pyrheliometer formula of the Linke turbidity factor. Meteorol. Rundsch. 33, 124-127.

Kasten, F., 1996. The Linke turbidity factor based on improved values of the integral Rayleigh optical thickness. Sol. Energy 56 (3), 239-244.

Khalil, S.A., Shaffie, A.M., 2016. Attenuation of the solar energy by aerosol particles: a review and case study. Renew. Sust. Energ. Rev. 54, 363-375.

Leckner, B., 1978. The spectral distribution of solar radiation at the earth's surfaceelements of a model. Sol. Energy 20,143-150.

Li, D.H.W., Lam, J.C., 2002. A study of atmospheric turbidity for Hong Kong. Renew. Energy $25,1-13$.

Linke, E., 1922. Transmission-koeffizient und Trübungsfaktor. Beitr. Phys. der freien Atmos. 10, 91-103.

López, G., Batlles, F.J., 2004. Estimate of the atmospheric turbidity from three broad-band solar radiation algorithms: a comparative study. Ann. Geophys. 22, 2657-2668.

Louche, A., Peri, G., Iqbal, M., 1986. An analysis of Linke turbidity factor. Sol. Energy 37 (6), 393-396.

Masmoudi, M., Belghith, I., Chaabane, M., 2002. Elemental particle size distributions: measured and estimated dry deposition in Sfax region (Tunisian). Atmos. Res. 63, 209-219.

Masmoudi, M., Chaâbane, M., Medhioub, K., et al., 2003. Variability of aerosol optica thickness and atmospheric turbidity in Tunisia. Atmos. Res. 66, 175-188.

Mavromatakis, F., Franghiadakis, Y., 2007. Direct and indirect determination of the Linke turbidity coefficient. Sol. Energy 81, 896-903.

Oliveira, B.F.A., Ignotti, E., Hacon, S.S., 2011. A systematic review of the physical and chemical characteristics of pollutants from biomass burning and combustion of fossil fuels and health effects in Brazil. Cad. Saúde Pública, Rio de Janeiro 27, 1678-1698.

Pedrós, R., Utrillas, M.P., Martínez-Lozano, J.A., et al., 1999. Values of broad-band turbidity coefficients in a Mediterranean coastal site. Sol. Energy 66 (1), 11-20.

Polo, J., Zarzalejo, L.F., Salvador, P., et al., 2009a. Angstrom turbidity and ozone column estimations from spectral solar irradiance in a semi-desertic environment in Spain. Sol. Energy 83, 257-263.

Polo, J., Zarzalejo, L.F., Martın, L., et al., 2009b. Estimation of daily Linke turbidity factor by using global irradiance measurements at solar noon. Sol. Energy 83, 1177-1185.

Portillo-Quintero, C., Sanchez-Azofeifa, A., Espirito-Santo, M.M., 2013. Monitoring deforestation with MODIS Active Fires in Neotropical dry forest: Na analysis of local-scale assessments in Mexico, Brazil and Bolivia. J. Arid Environ. 97, 150-159.

Power, H.C., Goyal, A., 2003. Comparison of aerosol and climate variability over Germany and South Africa. Int. J. Climatol. 23, 921-941.

Rahoma, U.A.L.I., Hassan, A.H., 2012. Determination of atmospheric turbidity and its correlation with climatologically parameters. Am. J. Environ. Sci. 8, 597-604.

Rapti, A.S., 2000. Atmospheric transparency, atmospheric turbidity and climatic parameters. Sol. Energy 69, 99-111.

Reboita, M.S., Gan, M.A., Rocha, R.P., et al., 2010. Regimes de precipitação na América do Sul: Uma revisão bibliográfica. Rev. Bras. Meteorol. 25, 185-204 (in portuguese).

Remer, L.A., et al., 2008. Global aerosol climatology from the MODIS satellite sensors. J. Geophys. 113, 1-18.

Rosenfeld, D., 1999. TRMM observed first direct evidence of smoke from forest fires inhibiting rainfall. Geophys. Res. Lett. 26 (20), 3105-3108.

Salazar, G.A., 2011. Estimation of monthly values of atmospheric turbidity using measured values of global irradiation and estimated values from CSR and Yang Hybrid models. Study case: Argentina. Atmos. Environ. 45, 2465-2472.

Satyamurty, P., Nobre, C., Silva Dias, P., 1998. South America. In: Karoly, D., Vincent, D. (Eds.), Meteorology of the Southern HemisphereMeteorological Monographs 27 (49). American Meteorological Society, Boston, pp. 119-139.

Scaramboni, C., Urban, R.C., Lima-Souza, M., et al., 2015. Total sugars in atmospheric aerosols: an alternative tracer for biomass burning. Atmos. Environ. 100, 185-192. 
Souza, J.L., Lyra, B.G., Santos, C.M., et al., 2016. Empirical models of daily and monthly global solar irradiation using sunshine duration for Alagoas State, Northeastern Brazil. Sustain. Energy Technol. Assess. 14, 35-45.

Teramoto, E.T., Escobedo, J.F., 2012. Análise da frequência anual das condições de céu em Botucatu, São Paulo. Rev. Bras. Engenharia Agrícola Ambient. 16 (9), 985-992 (in portuguese).

Trabelsi, A., Masmoudi, M., 2011. An investigation of atmospheric turbidity over Kerkennah Island in Tunisia. Atmos. Res. 101, 22-30.

Uscka-Kowalkowsk, J., 2013. An analysis of the extinction of direct solar radiation on Mt. Kasprowy Wierch, Poland. Atmos. Res. 134, 175-185.
Videla, F.C., Barnaba, F., Angelini, F., et al., 2013. The relative role of Amazonian and nonAmazonian fires in building up the aerosol optical depth in South America: a five year study (2005-2009). Atmos. Res. 122, 298-309.

Wen, C.-C., Yeh, H.-H., 2009. Analysis of atmospheric turbidity levels at Taichung Harbor near the Taiwan Strait. Atmos. Res. 94, 168-177.

WMO - World Meteorological Organization, 2008. Guide to meteorological Instruments and Methods of Observation. WMO-n ${ }^{\circ} 8$, Seventh Edition, 157-197, Geneva, Switzerland.

Zakey, A.S., Abdelwahab, M.M., Makar, P.A., 2004. Atmospheric turbidity over Egypt. Atmos. Environ. 38, 1579-1591. 